\title{
The paradox of managing autonomy and control: An exploratory study
}

\author{
G. Gilbert and M. Sutherland* \\ Gordon Institute of Business Science, \\ University of Pretoria, Pretoria 0001, Republic of South Africa \\ sutherlandm@gibs.co.za
}

\begin{abstract}
Managers are frequently offered conflicting advice as to how to increase organisational success. One of these complex dilemmas is whether to grant employees autonomy, which may lead to self-management and empowerment or alternatively, exercise control which may enable managers to retain a well-focussed and goal driven workforce. This research focuses on the key factors that influence the various combinations of autonomy and control and their respective outcomes. Qualitative exploratory research was conducted using in-depth interviews with 16 leading South African management and Human Resource experts to uncover their insights regarding this dilemma. The findings suggest that combinations of autonomy and control can co-exist. Management are able to create environments with high levels of autonomy whilst simultaneously retaining high levels of monitoring and oversight when the management control is indirect. It was found that the seemingly contradictory practices of autonomy versus control are a paradox, not a dilemma. Seventeen factors were identified that influence the different levels of autonomy and control in organisations.
\end{abstract}

*To whom all correspondence should be addressed.

\section{Introduction}

Organisations need to differentiate themselves from their competitors and one of the key levers is the way they manage employees to gain results. Executives and managers are inundated by a plethora of management theories, philosophies and models many of which offer contradictory advice. One dilemma managers are confronted with is whether to grant employees autonomy or to use control to guide their performance. One option is to introduce high levels of autonomy, where managers empower employees to self-manage their outputs. Alternatively, employees may perform better in an environment with high levels of control, where managers exercise a tight, autocratic management style. The necessity of balancing the seemingly contradictory tensions of autonomy and control has steadily increased with the exponential complexity within the business environment (Gupta, Smith \& Shalley, 2006). Many motivation and control theories have attempted with varied success to uncover the quintessential principles that increase individual and organisation performance (Attridge, 2009; Klein, 1989).

Although some literature has dealt with the subject of autonomy and control (Ryan \& Deci, 2000; Tyler \& Blader,
2005; Falk \& Kosveld, 2006; Ball \& Callaghan, 2012) no substantive consensus seems to exist regarding the means with which to manage the dilemma and achieve the right balance between autonomy and control. This study considers the apparent tension between the two opposing management views and attempts to clarify whether the approaches are mutually exclusive or whether it is possible to combine the benefits of both to strike an optimal balance. It also seeks to understand factors which influence combinations of autonomy and control depending on the circumstances (Tyler \& Blader, 2005; Hexmoor, 2002; Ball \& Callaghan,2012).

Managers may feel compelled to make a fundamental decision regarding their positioning of their management style having to choose an "autonomy" type approach or a "control" type. This dilemma is represented below in Figure 1. This model suggests that the closer a manager would come to either of the polar extremes on the continuum, the closer the management style would be to a purist, mutually exclusive style with each style containing its unique characteristics and outcomes. Management may grapple with this dilemma by toggling between autonomy and control. 
Alternatively this management problem can be graphically represented as in Figure 2. This model depicts combinations of autonomy and control management practices whereby the two respective forces can co-exist. There could be movement between the combinations based on a spectrum of influencing factors with alternative outcomes.

This leads to a complex problem: is it possible for a manager to give high levels of autonomy whilst simultaneously practising high levels of control? The key factors that influence the degrees of autonomy and control are not clear; consequently, management can be faced with a series of trial and error attempts to establish the correct balance. The consequences of this dilemma can be far reaching. This study considers empirical evidence based on interviews with experts in the field of management and human resources to unearth a deeper understanding into which of the above models is the more appropriate and what elements might contribute towards influencing a manager to adopt a particular management style.

\section{Literature review}

McGregor (1960) seminally postulated that a manager's belief in the functioning concept of employees will significantly influence his leadership style. He proposed a pioneering theory of two opposing, mutually exclusive perspectives; Theory X and Theory Y leaders. According to Larsson, Vinberg and Wiklund (2007) Theory X leaders believe their employees need to coerced, controlled and directed to force them to expend effort toward organizational objectives. The Theory Y managers believe employees will exercise self-direction and self-control in the service of objectives to which he is committed. Half a century later Hamel (2007) found that management seem to have too much management and too little freedom and that managers find it easy to compel people to be obedient and diligent, but they struggle to make them creative and committed.

Smith and Lewis (2011), state that tensions are inherent and persistent within organisations. Many authors emphasize the broad spectrum of dilemmas that management face (Berry \&
Hülsmann, 2004; Costa, 2005; Sieber, 2008, Serratta, Bendixen \& Sutherland, 2009; Andriopoulos \& Lewis, 2009; Farjoun, 2010; Smith \& Lewis, 2011). The terms "dilemma", "paradox", "ambiguity", "polarities" and "complexity" can refer interchangeably to contradictory forces or tensions that have the potential to influence a specific outcome. However, research seems to emphasise certain nuanced differences between the respective terms (Smith, 2000; Lusher \& Lewis, 2008; Smith \& Lewis, 2011).

As organisations become larger, traversing geographic boundaries, the business environment has inevitably become more complex. This implies more contradictory stimuli that need to be assessed and processed (Boyacigiller, 1990; Smith \& Lewis, 2011) with multiple stakeholders views needing to be considered. Within this complex environment, the ground is fertile for ambiguity. Ambiguity involves uncertainty or contradictions that cannot be resolved or reconciled. It also includes the deficiency of an agreement on boundaries, clear principles or solutions (Alvesson, 1993). Managers regularly make judgments and choices within this ambiguity by constantly assessing the differential weightings of the potential probabilities (Einhorn \& Hogarth, 1985) with competing stakeholders demanding attention. Leaders' responses to these tensions may be a fundamental determinant of an organisation's success (Smith \& Lewis, 2011).

The concepts of paradox and dilemma are closely related and have certain overlaps. The term "dilemma" will typically involve choosing between two conflicting alternatives. Fontin (1997) asserts that a dilemma is a decision making situation which is characterised by two reasonable options, for which equal, but contradictory substantiations can be found. Smith and Berg (1987) states that a dilemma can create a sense of paralysis because it implies that a choice must be made between polarities each having associated costs and benefits. Lusher and Lewis (2008) find that a dilemma contains potential for resolution, as the basis of a dilemma is an either/or choice where a decision must be made between two dissimilar options. A dilemma is illustrated in Figure 1 above.

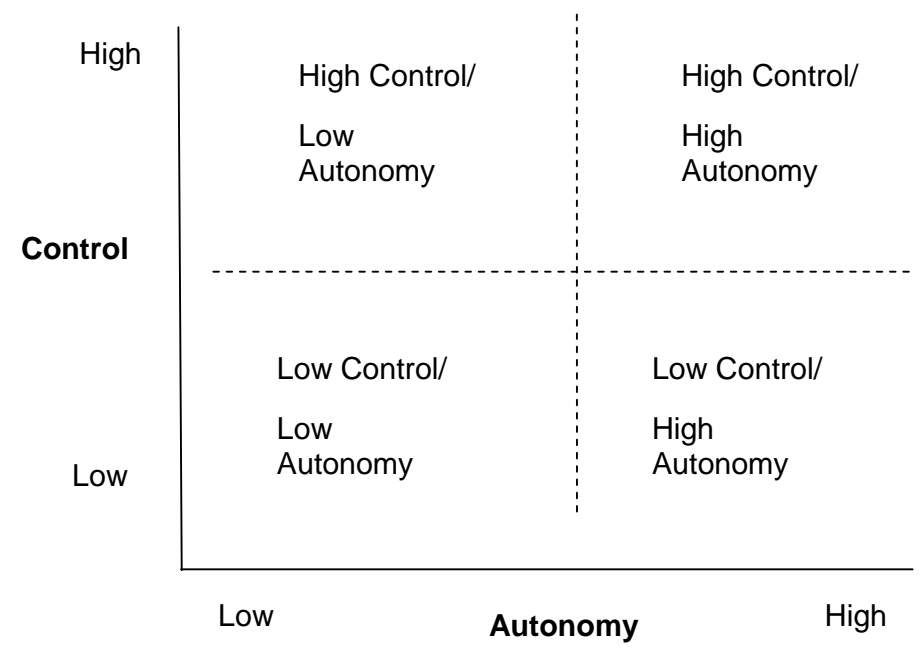

Figure 2: The dynamic management paradox model 
The literature has increasingly embraced the term "paradox management" (Lewis, 2000; Andriopoulos \& Lewis, 2009). Paradox may be defined as "contradictory, yet interrelated elements (dualities) that exist simultaneously and persist over time: Such elements seem logical when considered in isolation, but irrational, inconsistent and absurd when juxtaposed" (Smith \& Lewis, 2011: 387). Lusher and Lewis (2008) found that pushing managers to explore dilemmas often caused their paradoxical nature to surface. The more managers stressed the positive of one side, the more this accentuated the opposite. Regarding the tension between delegation and control, Smith and Lewis (2011) suggest that the more managers discussed the value of delegation to empower employees, the more this highlighted the need for control to ensure efficient implementation. Some examples of paradoxes where managers are encouraged to embrace opposing tensions simultaneously are between collaboration and competition (Rijamampianina \& Carmichael, 2005), long-term versus short-term concerns (Serretta, Bendixen, \& Sutherland, 2009), exploitation versus exploration (Andripoulos \& Lewis, 2009) and stability and change (Farjoun, 2010). Smith and Lewis (2011) find that a dynamic equilibrium should be purposefully sought to balance the persistence of conflicting forces in order to increase sustainability. A paradox is illustrated in Figure 2 above.

A key characteristic of a paradox is that there may be a short term way of balancing the competing forces but there is never a long term solution (Smith \& Lewis, 2011). Consequently, it is imperative for managers to transform their mind-sets to understand that "the world will increasingly demand that they manage paradoxes rather than solve problems" (Rhinesmith, 2001:4). Lusher and Lewis, (2008) suggest that managers should adopt a "paradox lens" to understand the contradictory managerial demands. Serretta, Bendixen and Sutherland (2009) find that dilemmas and paradoxes can only be managed and not solved.

Johnson (1996:13) asserts that "polarity management", similarly to paradox management, involves managing sets of opposites which cannot function independently. He says the two sides of a polarity are interdependent: one cannot choose one solution and neglect the other. He finds that polarity cuts through the "either/or" decision towards an "and" decision combining the positive aspects of both polar opposites, whilst managing the negatives. Collins and Porras (1994:44) state that "highly liberated companies liberate themselves with the Genius of the AND - the ability to embrace both extremes of a number of dimensions at the same time. Instead of choosing between A OR B, they figure a way to have both A AND B". Similarly Lewis (2000) suggests in paradoxical thinking the tension because opposing solutions need to be interwoven to achieve a united result. A paradox embodies the "and" mind-set as opposed to an "either/or mindset" of a dilemma.

Autonomy can be defined as the experience of "integration and freedom" (Ryan \& Deci, 2000: 231) and may refer to individuals or teams. Autonomy is a common and deep seated need rooted in the psyche of all human beings and is an important component that motivates employee performance (Pink, 2009). Autonomy, empowerment and self-management are all expressions of the notion that employees have the ability to achieve results through their own striving and independence. Employees that work under managers that grant high levels of autonomy, find greater job satisfaction and employee well-being and are more likely to achieve sustainable high performance (Pink, 2009; Hamel, 2007; Baard, Deci \& Ryan, 2004). However, the empirical link between autonomy and employee performance remains inconclusive (Verhoest, Peters, Boukart \& Vershuere, 2004). However, Baard et al. (2004), in a study of 320 small businesses, half of which granted workers autonomy, the other half relying on traditional control management, found that companies that offered autonomy grew at four times the rate of control-orientated companies. However, Langfred (2007) states that whilst employees may enjoy the freedom of a self-managed working environment, it may in fact impact negatively on organisational goals.

Dewettinck and Buyens, (2006) defined behavioural control as the extent to which managers monitor, direct, evaluate and reward employee activities within organisations and that it plays a strong role in optimizing the workplace. According to Tyler and Blader (2005) organisations rely on employees to follow formal rules and procedures via ensuring that management controls are in place. Harris and White (1987) found that the core management infrastructure for any large, complex dynamic system is command and control. Simons (1995) mentions 4 levers of control that managers may pull in different situations; belief systems, boundary systems, diagnostic control systems and interactive control systems. Taylor (2010) found that if an external locus of control is forced on an individual, it will reduce the goal oriented behaviour as well as levels of trust and consequently their performance. Falk and Kosveld (2006) found the majority of individuals display control adverse behaviour and state that companies should consider carefully the hidden costs of control. They found payoffs from high control come earlier, are more certain and easier to achieve; consequently, organisations tend to favour tighter rule over autonomy. However, control may be perceived as rigid, suffocating and stifling (Ritzer, 1993) but it has clear benefits and is often the default management practice (Harris \& White,1987). Companies across the world have adopted Kaplan and Norton's (1996) balanced scorecard management tool to help to control employees' performance.

Is it possible for management to balance autonomy and control, two seemingly opposite management approaches? Studies focused on this dilemma seem to be ambiguous and inconclusive (Dewettinck \& Buyens, 2006; Haas, 2010). Langfred (2004) asserts that even if employees have high levels of autonomy, some monitoring of employees should be in place to reduce process loss and coordination errors. Wageman (1995) argues that the leader must be responsible for setting the goals, creating a framework and structure and should then grant employees autonomy to perform within these guidelines. O'Reilly and Tushman (2007) and Andriopoulos and Lewis, 2009) refer to ambidexterity as the ability to successfully manage the conflicting tension between exploitation (control) and exploration (autonomy). 
There is evidence that organisations with structures and processes that enable employees to engage in exploration and exploitation simultaneously, rather than separately or sequentially have a higher propensity for more engaged employees. Dewettinck and Buyens (2006) note the preliminary evidence that both empowerment and management control may be invaluable in optimising performance within an organisation. Smith and Lewis (2011) demonstrate the need for studies which investigate paradoxical tensions to display contextual richness.

Managers may be pre-disposed to autonomy or control based on a variety of factors. Certain trait-like tendencies are reasonably reliable in predicting whether individuals will lean towards control or autonomy management styles (Taylor, 2010; Lee, McInerney, Liem \& Ortiga, 2010; Millikin, Hom \& Manz, 2010). The higher the level of trust in a team or an organisation the less likely will be the need for monitoring and control (Langfred, 2004; Nayar, 2010). Langfred (2004:386) says the personality traits of trust are "benevolence, honesty, and competence". Shared beliefs and organisational culture have a strong influence on the decisions and behaviour of managers and employees (Van den Steen, 2010). Autonomy may be more important for some jobs and less critical for others (Langfred, 2007; Colquitt, Janz \& Noe, 1997). Jobs that are very task and process orientated have less need for autonomy than perhaps an innovative orientated job. A specific industry may also lend itself to more autonomy practices or tight management practices (Cohen, Ledford \& Spreitzer, 1999). The IT software industry may have a natural pre-disposition to autonomy whilst the banking industry operates in a highly regulated and intense risk management environment.

The purpose of this research is to assess if managing the two diverse forces is a dilemma or paradox. How should managers successfully negotiate and toggle between the two opposing forces? The literature review has provided part of the "what", this research project attempts to uncover further insights regarding the "what" and proposes some guidelines to the "how" and the "why".

\section{Research questions}

Research Question 1: Are managers able to adopt mutually exclusive autonomy or control management practices?

Research Question 2: What are the outcomes of adopting a mutually exclusive, autonomy or control management practice for employees and organisations?

Research Question 3: Are managers able to simultaneously combine autonomy and control management practices?

Research Question 4: What are the possible outcomes of simultaneously adopting autonomy and control type management practices for employees and organisations?

Research Question 5: How can high autonomy and high control be achieved simultaneously?
Research Question 6: What are the determining factors that influence managers to adopt autonomy and/or control management practices?

\section{Research methodology}

As there is a dearth of empirical evidence about the dilemma being studied an exploratory qualitative research approach was used. Saunders, Lewis and Thornhill (2009) stress the use of a qualitative design for studies that are based on transferring insights and drawing deeper meaning drawn out of experts. Blumberg, Cooper and Schindler, (2008) and Tharenou, Donohue and Cooper (2007) state that studies of a qualitative nature gather new insights, explore not yet understood phenomena to build theory in the field of management. Zikmund (2003:54) states that "Exploratory research is conducted to clarify ambiguous problems" and in order to gain greater understanding of a concept or to crystallise a problem.

In-depth semi-structured interviews were used. A key benefit of face-to-face interviews is the likelihood of obtaining complete and precise information, which can be clarified and confirmed (Zikmund, 2003). Individual interviews are capable of exploring a new topic in order to develop a new hypothesis or concept and to identify important characteristics and drivers of a phenomenon (Blumberg et al., 2008). Typically, the interviewer will probe and delve into the subject to unearth a wellspring of ideas, thoughts and insights (Tharenou et al., 2007).

The interviewees were leading South African company executives and respected human resource specialists. The executives selected had a sound reputation based on their extensive experience and deep understanding of the complexity of managing employees for results. The human resource specialists were selected based on their practical and theoretical application of people practice models and all had experience of the autonomy/control dilemma. Many of the interviewees are nationally known business authorities. The interviewees were selected from diverse industries and from organisations of different sizes, structures and cultures in order to reduce concentration bias. The industries represented were; finance, retail, mining, manufacturing, health care, academia, consulting and information technology. Thus purposive sampling (Zikmund, 2003) was used where sample members conform to some criteria, i.e. acknowledged experts in the management of people. A nonprobability sample of nine executives and seven experts in human resources was interviewed. The sample of 16 was deemed sufficient once the themes and insights of the experts began to converge and become increasingly repetitive.

The data was collected via 15 face-to-face interviews and one telephonic interview as the interviewee was located in Namibia. Each interview lasted between 45 minutes and an hour depending on the flow of the discussion. The use of an interview guideline ensured interview consistency and interviewer neutrality (Denzin \& Lincoln, 2005). It contained ten open-ended questions to obtain insights relating to the six research questions. The sequence of the questions varied from one interview to the next depending 
on the interviewee's flow of thought (Tharenou et al., 2007). Additional questions were used to explore issues that were unique to a particular organisation or industry and probing techniques were used to stimulate the dialogue (Blumberg et $a l ., 2008)$. The interviewees were highly engaged in the conversations trying to unravel the associated complexities. It was clear that the dilemma under review was a challenge that all the interviewees had grappled with to varying degrees.

All the interviews were recorded and then transcribed to enable the verification and analysis process. Content analysis was used which Welman, Kruger and Mitchell (2005:221) define as "a quantitative analysis of qualitative data" allowing the researcher to identify the themes and patterns and then to synthesise them into findings. This technique is unobtrusive and non-reactive (Marshall \& Rossman, 2006) allowing the researcher to infer meaning from the data in a way that demonstrates logic. A coding frame designed in Excel was formulated to map the data from the interviews to the six research questions. The expected outcome of this type of analysis is "a narrative or story" highlighting the new information and insights drawn from the interviews (Tharenou et al., 2007: 52).

The possible limitations of this study; the sample may not be fully representative of the population as lower level managers may have a different view on the management dilemma, the unspoken influence of the interviewer can distort and sway the interviewee towards a pre-determined result (Blumberg et al., 2008) and the analysis of qualitative data can result in the findings being influenced by the researcher's interpretation of the data (Denzin \& Lincoln, 2005).

\section{Results}

Research Question 1: Are managers able to adopt mutually exclusive autonomy or control management practices?

The interviews highlighted the emphatic view that autonomy and control are not mutually exclusive. Eleven of the interviewees felt that it is not possible for managers to adopt a mutually exclusive autonomy or control management approach, whilst three interviewees felt that it is possible in very specific circumstances.

Eleven interviewees felt that an environment of absolute autonomy with no control will completely disempower managers. Employees will be left to their own devices which could significantly damage the organisation. Interviewees also felt that it is critical for managers to have the ability to monitor and oversee employee performance to ensure alignment with organisational targets and goals. Employees also need to have regular structured feedback and guidance from managers regarding their role and objectives.

Interviewees felt that total control with no autonomy would not be feasible and equally destructive as it would be too restrictive. Consequently, all organisations, even those that aspire to employ high levels of autonomy, will need to have some level of control in place. Two of the interviewees expressed their views as follows; "Neither of these are two independent poles in a particular leadership context, neither of these poles exist without the other effectively." "I think it is a continuum as opposed to two opposites. It is a continuum and in some situations the best recipe is probably a mixture of both."

Three interviewees felt that either extreme autonomy or control is generally not viable, however managers could adopt absolute autonomy or control in very limited and specific circumstances as expressed in "I think if you are brand new on a job and the consequences of making a mistake are quite high, then I think it is appropriate and only under those very specialised circumstances, to have total control. Or if you are in a crisis situation or where there is a life and death threat, there are certain circumstances, but I think they are the exception rather than the rule".

Absolute autonomy is discussed theoretically in terms of power by Hexmoor (2002) with no empirical evidence. However, absolute control could not be found in the literature. Although, the applications mentioned above are rather narrow, there may be of benefit in broadening the usefulness of either one of the polar extremes to accommodate unusual circumstances. However, all interviewees felt that in the majority of cases, autonomy and control should co-exist. This indicates that the interviewees view the control versus autonomy debate not as a dilemma where one has to make the choice between two alternatives but as a paradox or duality where managers have to simultaneously use both seemingly contradictory management practices (Lewis, 2000; Lusher \& Lewis, 2008; Luo \& Zhang, 2008; Farjoun, 2010).

Research Question 2: What are the outcomes of adopting a mutually exclusive autonomy or control management practice for employees and organisations?

Whilst the experts felt that autonomy and control may have great value each practice in isolation can have debilitating consequences. Eight interviewees noted that the stifling nature of total control which would neutralise any positive benefits via sapping employee's energy and engagement with the organisation. Employees would then fulfil their tasks with minimum effort. The organisation's culture will be characterised by low levels of trust and collaboration and failures will be hidden because of the perceived consequences resulting in an environment of low innovation. One interviewee said "I think that the consequences of that are quite dire ... by having overcontrol you remove creativity, you remove empowerment, you remove initiative and everything comes down to 'you want me to act like a robot I will act like a robot but you will land up getting about 40 or $50 \%$ of my potential output; the discretionary effort I have will not be spent on this",". Ritzer (1993) finds that this type of control has the danger of neglecting the human dimension and sees employees as substitutes for automated machines. Taylor (2010) and Falk and Kosveld (2006) find that the majority of employees actually display control adverse behaviour resulting in poor performance. 
Five interviewees felt that control may have some "quick wins" and short term benefits regarding organisational efficiency and effectiveness and that it can give management a sense of power. The need for consistent and efficient performance will entice managers to overlook the human dimension and focus on getting the job done. However, over time, excessive control will inevitably become detrimental to an organisation and is thus not sustainable. As noted by one expert: "A very controlled environment can be very efficient, sometimes for weeks, sometimes for months, sometimes for years, but eventually I think it has a systemic feedback which is not sustainable." Falk and Kosveld (2006) exhort managers to consider carefully the "hidden costs" of control on the long term sustainability of the organisation.

On the opposite pole, two interviewees felt that too much autonomy can introduce excessive risk into an organisation. They found that a lack of guidance, measurement, structure and co-ordination can disrupt high performance and that managers need to steer employees with regular feedback. As one interviewee cautioned "...increased autonomy can give rise to increased risk as well as potential inefficiency because you are not harnessing things as well as you could". Langfred $(2004 ; 2007)$ noted that high individual autonomy within teams can lead to lower performance. He articulated the danger of excessive autonomy by highlighting the importance of giving employees the tools and skills to manage themselves to avert employees from drowning in their own independence.

The experts thought that the negative consequences of either extreme of autonomy or control over time will neutralise the possible benefits of management's positive intent and are thus not sustainable. Both poles have negative consequences for both employees and organisations. This again supports the view that managing autonomy versus control requires managers to adopt a "paradoxical lens" (Lusher \& Lewis, 2008) rather than view the choice as a dilemma.

Research Question 3: Are managers able to simultaneously combine autonomy and control management practices?

All sixteen experts agreed that balancing the right combinations of autonomy and control is essential for ensuring high performance of employees and organisations. Managers don't have to choose between the two extremes; astute managers are able to straddle both, testing different combinations for different situations. The goal of management is to constantly marry the two factors in a "yin yang" relationship in an ever-changing dynamic manner depending on a range of factors to achieve sustainable performance. Combinations of the two could vary from high autonomy and high control to low autonomy and low control with various permutations between the two extremes.

The interviewees felt that the notion of management control contains essential attributes that contribute to the long term success of an organisation whilst autonomy will also include vital elements essential to the company's ability to unleash the potential of their employees. The experts concurred that the two critical management practices are not mutually exclusive, rather, both are simultaneously crucial. They can and must co-exist. Hence the relationship between control and autonomy is paradoxical and not a dilemma (Smith \& Lewis, 2011). Haas (2010) and Collins and Porras (1994) speak about the genius of the AND in combining high levels of autonomy and control. Managing the dilemma effectively demands an understanding that neither of these two poles exist without the other.

Fifteen interviewees felt that the attributes of control are exceptionally valuable when combined with autonomy to drive employee and organisational performance. Managers need to feel a level of control whilst employees need to feel a level of freedom. Control can refer to the direct control that managers enforce on employees, also known as micromanagement. This type of control is commonly negatively associated with a traditional hierarchical management structure and coercive power. Control can also have positive connotations when it is an indirect influence that management can exert in a more subtle way. This type of control has the benefit of giving management the necessary oversight without creating a negative, prescriptive working environment. Examples of indirect control would be the culture of the organisation, values, guiding principles and the performance management systems that focus on outputs as opposed to tasks. Managers can develop a level of comfort from monitoring from a distance and inculcating a strong culture of accountability. When control is focused on indirect influence high autonomy and high control can coexist. Management must determine and communicate the "what" and employees the "how". As two interviewees said; "You are codifying control, but codifying it in a kind of voluntary way." "We have a value system here, that is how we exercise control...".

Simons (1995) enumerated 4 levers of control. The direct levers included boundary systems that had formally stated rules and prescriptions as well as interactive control systems that managers use to involve themselves regularly and personally in the activities of employees. The indirect levers enabling autonomy to flourish include diagnostic control systems. These systems are able to monitor outcomes as well as belief systems which define values, purpose and direction. Nayar (2010) supports the notion that culture can be an effective indirect control mechanism that helps foster autonomy. Another example of an effective indirect control mechanism is the balanced scorecard of Kaplan and Norton (1996) which allows mangers to track and monitor a broad range of employee and organisational metrics to ensure that the employee activities are aligned to performance goals in order to drive strategy.

Six interviewees clarified the importance of autonomy in combination with control as having the ability to breathe life into employees and organisations. They felt that autonomy helps to create a culture of high energy and employees will feel motivated and empowered if managers grant them independence to achieve their joint goals. One expert said "So the orientation towards the unleashing of human energy is huge, and I believe too that discretionary effort comes from intrinsic motivation, not extrinsic motivation." Autonomy involves more of a partnership between manager and employee than a hierarchical downward manager/subordinate relationship. Autonomy will engender 
intrinsic motivation in employees as they will be consulted and included in the decision making process (Ryan \& Deci, 2000; Pink, 2009). Hamel (2007) felt that employees within an environment of autonomy will be motivated to strive to achieve high performance in a sustainable manner. Ambidexterity (Andriopoulos \& Lewis, 2009) is the ability to simultaneously leverage paradoxical forces until they become virtuous cycles.

Research Question 4: What are the possible outcomes of simultaneously adopting autonomy and control type management practices for employees and organisations?

Eleven interviewees felt that the outcomes of simultaneously adopting combinations of autonomy and control would be positive for organisations. The experts said that the management approach towards the quandary under investigation is not the linear dilemma shown in Figure 1 above. Rather, managers experiment with different combinations in different circumstances. The experts said that there is no ideal balance, the tensions are dynamic and as the internal or external environment adjusts the combination should change. As a result of the interviews Figure 2 was enhanced into Figure 3 showing four different permutations of the two inter-related forces with each quadrant named to identify the four options.

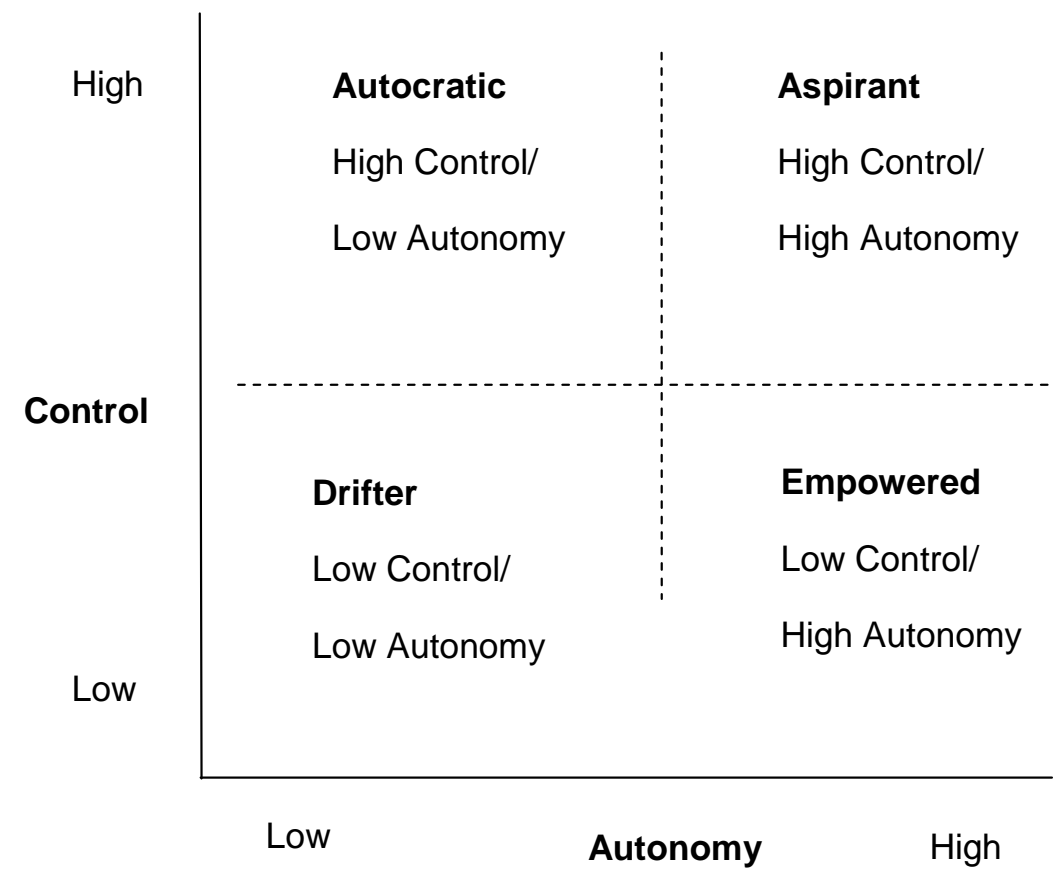

Figure 3: The autonomy and control interdependence model

The top left quadrant reflects an autocratic type of management style reflecting high control with managers not allowing the levels of autonomy to increase as they will perceive that as losing control. Organisations in this quadrant typically have a rigid hierarchical structure with highly regulated processes, policies and procedures. Some parts of the banking industry which is highly regulated industry would fit in this quadrant. Management will need to expend large amounts of time managing employees' activities and staff will become increasingly disengaged. The advantage of this approach for management is that it gives managers an efficient management tool to ensure compliance. Micro-management and direct control methods will be used that usually stifle innovation and it will be unusual for employees to contribute any discretionary effort. Thus this managerial style is not broadly sustainable.

The bottom left quadrant is characterised by managers that are drifters. This approach depicts a disinterested, casual and disengaged management style, characterised by low control as well as low autonomy. This management approach contains little benefits for either employees or companies. Organisations that foster this type of management culture are unlikely to be successful.

The bottom right quadrant portrays an empowered style characterised by high levels of autonomy with low levels of control. Employees are granted high levels of freedom to be creative and innovative and are expected to have high levels of self-management to drive organisational performance. Examples of organisations in this quadrant are the high-tech and creative industries. Although employees may feel empowered the low levels of control could hamper management's ability to adequately supervise employee performance and to co-ordinate activities across the company. Unbridled freedom without applied guidelines can be more destructive than tight control. There is likely to be low levels of consistency and standardisation across the organisation which could impact a broad range of stakeholders. 
The top right quadrant reflects the high control and high autonomy combination, termed the aspirant manager. In this paradoxical relationship, management are able to retain control whilst employees are engaged, focused and motivated. In this quadrant the control is indirect control via a strong culture, values and guidelines that do not engender the negativity commonly associated with direct control. Indirect control provides the critical oversight and monitoring which allows for the effective managing of risk whilst co-ordination across the organisation is also achieved. Employees benefit by enjoying autonomy within predetermined deliberate guidelines. If managers are able to strike the correct balance, employees are well placed to increase their personal performance in a sustainable and enduring way, enabling the company to achieve its corporate objectives; a win-win partnership.

Research Question 5: How can high performance and high control be achieved simultaneously?

A critical insight developed from the experts is the notion that self-actualisation and job fulfilment are attainable in an environment of high autonomy and high control. They said that clear, unambiguous communication is far more effective than a series of prescriptive rules and policies. Employees will respond positively when given freedom within a well understood "brief". They clarified the distinction between the "what", referring to the notion of indirect control and the "how" referring to the granting of autonomy. Management are then able to leverage employees' inner drive whilst maintaining reasonable oversight. An expert explained this "When your governance is good like McDonalds, when your systems are codified the management are more relaxed to explore new things and the business can scale."

The experts felt that indirect control leads to more engaged employees who are prepared to put in discretionary effort but within the parameters established by management. Using indirect control prevents managers being bogged down with monitoring activities and they are thus enabled to focus more strategically. The indirect control factors that will foster high levels of autonomy and control are; well communicated vision and strategy for the organisation, strong culture of trust and accountability, the emotional maturity of the manager and well developed performance transparent management systems. Indirect control that will engender high levels of autonomy will be most effective when employees display a personality that embraces autonomy, emotional maturity, competence to do the job and a willingness to learn and grow.

The experts felt that reputational and operational risk can be monitored through indirect control, allowing employees space to experiment within limitations. Companies that allow employees to explore alternative avenues and sometimes fail have a greater propensity to generate the innovations which give organisations a powerful competitive advantage. At the same time a framework gives employees the security of knowing the boundaries and limitations of the company's "playing field". Within this defined structure employees have the freedom to engage deeply in their jobs. These factors create the enablers for autonomy and control to continuously reinforce and leverage off each other in a healthy tension that nurtures a symbiotic relationship and a unique and sustainable competitive advantage.

Interviewees felt that a combination of high autonomy and high control should be aspired to by most managers. Two experts said "So I think leadership has to provide control in the format of direction, but control should not be without the presence of autonomy and autonomy should not be without the presence of control." "I think very often it's the processes and the systems that allow for the autonomy. Maybe this is the paradox, if you've got good controls in place, you can be more autonomous."

Lambe, Webb and Ishida (2009) suggest that both autonomy and control enable employees to develop a sense of empowerment within a defined framework resulting in highly engaged employees. Simons (1995) asserts that belief systems would allow employees to grow and flourish within a culture that mitigates the risk of non-compliance. The writings of Johnson (1996) and Smith and Lewis (2011) highlight the benefits of the "and" instead of the "or". Dewettinck and Buyens, (2006) note that there seems to be some preliminary evidence that both autonomy and management control may be invaluable in optimising performance within an organisation.

Managers need to develop essential paradox management skills in order to simultaneously achieve high levels of control and autonomy. They need to view the forces as complimentary and both should be visible and operational. The outcome of successfully merging the two perspectives will lead to a constructive, collective engagement that will enhance employee as well as company performance.

Research Question 6: What are the determining factors that influence managers to adopt autonomy and/or control management practices?

In order to manage the paradox managers need to understand the factors that influence the appropriate selection of the autonomy/control mix. The interviewees mentioned seventeen factors which are wide-ranging and offer insights for managers to consider when wanting to optimise the paradoxical equation. The factors shown in Table 1 were ranked according to the number of responses.

These factors can be re-categorised into the factors associated with; the company, those intrinsic to the manager; and others related to the employees, as shown in Table 2. These factors show the complexity of competencies required to manage the paradox between autonomy and control and are discussed in detail below. 
Table 1: Factors influencing the management choice

\begin{tabular}{c|l|c}
\hline Ranking & $\begin{array}{c}\text { What are the determining factors } \\
\text { that could influence a manager to } \\
\text { adopt autonomy and/or control } \\
\text { management practices? }\end{array}$ & $\begin{array}{c}\text { Number of } \\
\text { Respondents }\end{array}$ \\
\hline 1 & The culture of the organisation & 14 \\
\hline 2 & Different industries & 12 \\
\hline 3 & Different levels and functions & 12 \\
\hline 4 & Personality & 11 \\
\hline 5 & Different companies & 10 \\
\hline 6 & Leadership & 10 \\
\hline 7 & Maturity of manager and employees & 9 \\
\hline 8 & Risk tolerance & 8 \\
\hline 9 & Employee competence & 8 \\
\hline 10 & Business environment & 6 \\
\hline 11 & Trust & 5 \\
\hline 12 & Structure & 4 \\
\hline 13 & Technology as an enabler & 4 \\
\hline 14 & Generational & 4 \\
\hline 15 & Size of business & 3 \\
\hline 16 & Performance management systems \\
\hline 17 & Ability to learn & 3 \\
\hline
\end{tabular}

\section{Organisational factors}

Fourteen respondents felt that culture of the organisation would be a significant factor that would aid in determining the right balance between autonomy and control. One interviewee said "If you have a culture that allows people to innovate, influence and create, it can be high control, high autonomy." The culture of an organisation is the intangible influence that a company develops over a period of time which can be used as an indirect control lever to provide a framework of parameters within which employees operate. Van den Steen (2010) and Nayar (2010) note the importance of developing a culture of trust, accountability and transparency to fuse together the efforts of management and employees toward a united goal.

Twelve interviewees felt that the type of industry that a company operates in will be a key determinant of the level of autonomy or control that is exercised. The banking sector, which is predicated on strong risk management and governance, may have a greater leaning towards control than in the advertising industry. One expert said "A creative industry may have lower control and higher autonomy because you want to leverage the creativity of the people and it is less important to have control." Cohen et al. (1999) found that managers will align their management practices according to factors inherent within the industry.

Ten interviewees felt that different companies within the same industry will use different methods of optimising the tension between autonomy and control in order to develop a distinctive competitive advantage. One interviewee said "You could have a strategic choice to be highly autonomous, to leverage knowledge, concept and diversity. So yes strategy would influence and be a factor. And that is a choice." A stand-alone business would be vastly different to the controls inherent in a multi-national company. The notion of different companies within the same industry using different levels of autonomy and control was not covered in the literature.

The level of maturity of a company will be influential. The older a company is, the more likely it is to have established policies and guidelines; a more controlled environment. Conversely, a younger company is usually more agile with a greater propensity for autonomy. Some interviewees felt that if the controls that are embedded in their business currently would have been embedded in the first few year of the business, the business would never have survived. Organisations at different stages of their life cycle could thus have different approaches to autonomy and control. This was not mentioned in the literature.

Eight interviewees discussed risk as being critically important. Companies that operate in a high risk industry will typically have an increased propensity for control in the form of compliance to company procedures, policies and rules. Whilst companies that encourage employees to make mistakes in order to foster a culture of innovation will be less risk averse and engender higher levels of autonomy. Government policies and regulatory bodies will also influence the level of control. They mentioned that employees with too much autonomy could unleash significant damage to a company's profit and reputation. The experts said; "I guess the biggest factor is risk." "Absolutely, risk is important, but I think you have to look at whether that risk is at a point in time or whether that risk is systemic." Risk as a determinant of autonomy and control was not emphasised in the literature.

Table 2: Factors influencing the balance between autonomy and control

\begin{tabular}{l|l|l}
\hline \multicolumn{1}{c|}{ Organisational factors } & \multicolumn{1}{c}{ Managerial Factors } & \multicolumn{1}{c}{ Employee Factors } \\
\hline Culture including level of trust & Personality & Personality \\
Company differences & Maturity & Maturity \\
Industry & Trust & Trust \\
Operating environment & Ability to learn & Ability to learn \\
Risk tolerance & Leadership style & Different levels and functions \\
Structure & & Generational differences \\
Technology & & \\
Size & & \\
Life cycle stage/maturity & & \\
Performance management system & & \\
\hline
\end{tabular}


Six interviewees felt that the socio-political environment that the company functions in will affect the management practices. Interviewees mentioned the autocratic manufacturing processes of China, the high power distance in Japan and low power distance when operating in Australia. Democratic, open societies will tend to encourage a more liberating and empowering business culture, whilst more draconian societies will be more inhibiting. An economy or industry in crisis may sway a company's management practices to a more controlled approach. The business environment was not a factor mentioned in the literature.

Five interviewees stated that the structure of a company and the chosen processes and systems will influence management preferences. Interviewees said "It's not just culture, it's the policies, systems and processes that you put around the management of people." ".The real discussion is what are you centralising, what are you decentralising?" "The core has to be stable and efficient and repetitive and routinised and the periphery has to be innovative and flexible and effective." A very hierarchical structure will encourage a command and control management style. Managers and employees with an inherent leaning toward granting self-empowerment will find this type of structure obstructive. Similarly, a flat and open structure will enable autonomy but increase risk. The influence of the structure of an organisation was mentioned by Smith and Lewis (2011) and Ball and Callaghan (2012) but they did not offer empirical evidence.

Four interviewees expressed the notion that greater levels of autonomy can be achieved if a company has embedded technology systems that automate effective indirect controls which allow managers to track day-to-day operations and results without being perceived negatively as directly controlling their employees. Two interviewees said; "It's vastly driven by technology that has enabled the people to have access to information and understanding the connection between things. Those connections in the past used to sit with the leaders but now people at all levels have that information." "This is the revolution that technology has brought, it is remote control." Technology thus enables the two management approaches to co-exist. The experts cautioned that if managers abuse technology to overcontrol employees, the benefits will evaporate and distrust of management will emerge. Technology as an influence is discussed by Ball and Callaghan (2012).

Four interviewees felt that the size of the business will impact the management practices; smaller, more entrepreneurial businesses will generally grant more autonomy as they need to be agile and won't have the budget to for elaborate processes and controls. Larger organisations tend to have more structure and a greater need to control risk by prescribing policies and procedures. These views were expressed as: “... you can't scale without delegating control, so they can scale by giving control to the people but they have really delegated control to the systems. The recipe works." "...size is a factor, because the bigger you are the more difficult it is to exercise the informal use of control." The influence of management approaches on ambidexterity was discussed by Andriopoulos and Lewis (2009).

Three interviewees felt that comprehensive performance management systems will affect the level of control and autonomy as they enable management to exercise high levels of indirect control through managing the outputs. The systems will allow managers to move their teams towards a high (indirect) control and high autonomy situation in which they can mitigate the risks that are associated with high autonomy. When managers allocate incentives based on performance, employees quickly understand the "rules of the game" and a meritocracy is established. Two relevant comments were; "...performance management of outcomes would influence this; if you have a good system like a balanced score card that would give you the control which may allow for greater degrees of autonomy in high risk environments." "...I think you would need to have the controls, the measures, the outputs quite clearly defined, and then maybe the means of getting there could be more autonomous." Kaplan and Norton's (1996) balanced score card allows managers to introduce indirect controls without the associated negative implications of tight management control. Simons (1995) refers to diagnostic and interactive control systems which assist managers to indirectly monitor performance.

\section{Factors pertinent to managers and employees}

Eleven interviewees felt that the personality of the manager and the employees will affect the level of autonomy or control. Individuals have different traits and characteristics which make them either naturally lean towards independence and self-management or a defined structure with a degree of rigidity. Managers will be more effective if they are able to align their management style with the personality of their employees to leverage their particular strengths. Interviewees said "For some people to work in a very confined regulated environment is fine because it gives them a comfort zone, there is no risk that they have to take, and it is all just follow the rules." "I mean take Myers Briggs, everyone is an absolutely unique individual and I guess the fascinating part about it is that how do you as a manager get the combination right." This supports that writings of Lee et al. (2010) and Millikin, Hom, and Manz (2010)

Maturity of both the manager and employees will play a role. Management will be more likely to grant autonomy to employees that are responsible and reflect a high level of independence. Managers with high levels of emotional maturity will be more likely to balance autonomy and control in an effective way. As one interviewee said; "I suppose probably the single most important thing is just to develop some level of emotional intelligence in managers..."

Five interviewees felt that autonomy and control will oscillate depending on the level of trust between managers and employees. If a manager trusts his employees, as a result of employees performing to expectations on a consistent basis, he will be more comfortable to grant them autonomy. If trust is broken, a tight management control style will be enforced until trust is re-established. Some 
comments in this regard were "Autonomy assumes trust." "So there is an equation for trust and it is something I have used a lot which says that trust is equal to credibility multiplied by intimacy divided by risk." Langfred (2004) and Nayar (2010) state that the higher the level of trust, the less likely will be the need for monitoring and control and that transparency is a critical component to break through the manager/employee divide.

Three interviewees felt that managers that are open to learning new ideas would invest time and energy learning how to empower their employees as opposed to managers that perpetuate the style that they are comfortable with. Employees who are able to learn how to do their job efficiently and effectively have less need for supervision and can be given more freedom. One interviewee said; "...learning and the ability to be open to that learning is probably the single most important thing”. Companies that invest time and effort in developing their staff will find that their managers are able to give their employees more autonomy. This insight was not highlighted in the literature.

\section{Management specific factor}

Ten interviewees felt that leaders and the executives in particular, have huge influence regarding the use of autonomy and control in their organisations. One interviewee comment in this regard was "The company is the same, the product is the same, everything is the same and the styles of the two leaders were diametrically opposed: one was a completely empowering one and one was a complete control fellow." Interviewees highlighted the situational leadership theory and cited it as a valuable tool to assist managers to leverage different management practices for different employees within the same team.

\section{Employee Factors}

Twelve interviewees felt that the level of the specific job will be a key factor. One interviewee said; "If you are in a very production environment, like here at our call centres, there is very little autonomy, how they speak and the rules that they follow is all scripted and codified. Yet you talk to our business analysts and they are making decisions on stuff that is fairly autonomous. It really does depend on the type of function." Literature regarding the specific level and job type support these findings (Langfred, 2007; Colquitt et al., 1997). Two interviewees highlighted the Stratified Systems Theory in which Jacques (1985) postulated that the level of work will directly influence the need for direct management control.

Eight interviewees felt that the competence of the employees is an important factor. Employees that are more skilled, confident and competent will not require as much management attention and control as employees that are still relatively new in their role. Too much supervision for competent staff will be stifling whilst too little supervision for trainee staff will lead to sub-optimal performance. One interviewee said "If I did not have confidence in the quality of management and people, I would impose control. With brilliant people, I relinquish control." This insight was not covered in the literature.
Four interviewees mentioned that generational differences will influence the autonomy and control mix. Managers from the "baby boom" era will have more of a tendency to adopt hierarchical practices whilst younger employees from the more recent " $\mathrm{X}$ and $\mathrm{Y}$ " will prefer a more autonomous management approach. An interviewee said; "We are starting to see the management of $Y$ generation and the $X$ generation like autonomy; they come to work when they want to come to work and they kind of distance themselves from the more standard organisations." Armstrong and Murlis (1998) discuss how the psychological contract between employees and organisations has moved significantly from a control and command style to a participative style during the 1990s.

\section{Conclusion}

Managers struggle to navigate the complexity of granting employees autonomy whilst still retaining control. The research findings contribute to the theory by identifying the complexity of the apparent conflicting management practices. The first contribution relates to the interdependence of autonomy and control. It is not a management dilemma of autonomy versus control in an absolute manner; rather autonomy and control paradoxically can and must co-exist to form a powerful management tool. Effective management is the ability to toggle the two management styles to optimise both options to increase employee engagement and organisational performance.

The second contribution relates to the understanding of control and autonomy. Direct and prescriptive management control may be an efficient management tool in the short term. However, over time, employees will disengage from the manager and the organisation. Similarly without clear guidelines absolute autonomy could degenerate into confusion and chaos. Therefore, management should grant autonomy by employing indirect control. Indirect control requires a deliberate and comprehensive plan to create a working environment that allows employees the autonomy they desire whilst simultaneously allowing managers to maintain the necessary oversight. This should result in a win-win outcome where employees will feel motivated and fulfilled, whilst management will have the necessary monitoring and control.

The third contribution relates to the seventeen factors that influence the levels of autonomy and control in organisations. Many of these factors were not mentioned in the literature.

Future research could; elicit responses from a sample of middle managers that may have a different perspective regarding the topic under review, develop devices to assist managers to successfully implement indirect control, and quantitatively assess the combinations of the seventeen factors which influence the paradox. 


\section{References}

Alvesson, M. 1993. 'Organization as rhetoric: Knowledgeintensive firms and the struggle with ambiguity', Journal of Management Studies, 30(6): 998-1015.

Anderson, E. \& Oliver, R. L. 1987. 'Perspectives on behaviour-based versus outcome-based sales force control systems', Journal of Marketing, 51: 76-88.

Andriopoulos, C. \& Lewis, M.W. 2009. Exploiation Exploration tensions and organizational ambidexterity: Managing paradoxes of innovation', Organization Science. 20(4): 696-717.

Armstrong, M. \& Murlis, H. 1998. Reward management: A handbook of remuneration strategy and practice. $4^{\text {th }}$ Edition. London: Kogan Page Ltd.

Attridge, M. 2009. 'Measuring and managing employee work engagement. Review of the research and business literature', Journal of Workplace Behaviour Health, 24(4):383-398.

Baard, P.P., Deci, E.L. \& Ryan R.M.. 2004. 'Intrinsic need satisfaction: A motivational basis of performance and wellbeing in two work settings', Journal of Applied Social Pyschology, 34(10): 2045-2068.

Ball, M. \& Callaghan, V. 2012. 'Managing control, convenience and autonomy: A study of agent autonomy in intelligent environments', Journal of Ambient Intelligence and Smart Environments. [online]

URL:http://www.iospress.nl/journal/journal-of-ambientintelligence-and-smart-environments/ .Advance online publication. Accessed April 2012.

Barrett, R. 2006. Building a values-driven organization: A whole system approach to cultural transformation. Amsterdam: Butterworth-Heineman.

Berry, A. \& Hölsmann, M. 2004. 'Strategic management dilemmas; its necessity in a world of diversity and change'. In SAM/IFSAM VII ${ }^{\text {th }}$ World Congress on Management in a world of Diversity and Change. Goteborg: SAM/IFSAM, pp. 1-43.

Blumberg, B., Cooper, D. R. \& Schindler, P. S. 2008. Business research methods. $2^{\text {nd }}$ Edition. New York: McGraw-Hill Education.

Boyacigiller, N. 1990. 'The role of expatriates in the management of interdependence, complexity and risk in multinational companies', Journal of International Business Studies, 21(3): 357-381.

Cohen, S. G., Ledford Jr, G. E. \& Spreitzer, G. M. 1999. 'Developing effective self-managing work teams in service organisations', Group \& Organisation Management, 24(3): 340-366.
Collins, J. \& Porras, J. 1994. Built to last: Succesful habits of visionary companies. New York: Harper Collins.

Colquitt, J. A., Janz, B. D. \& Noe, R. A. 1997. 'Knowledge worker team effectiveness: The role of autonomy, interdependence, team development, and contextual support variables', Personnel Psychology, 50(4): 877-904.

Costa, A. 2005. 'The ambiguities of performance management'. Unpublished MBA research report. Gordon Institute of Business Science, University of Pretoria.

Denzin, N. \& Lincoln, Y. 2005. The Sage handbook of qualitative research. California: Sage Publishers.

Dewettinck, K. \& Buyens, D. 2006. 'Linking behavioral control to employee outcomes: Testing two explanations using motivation theories'. In Academy of Management Proceedings. Best conference paper 1.

Einhorn, H. \& Hogarth, R. 1985. 'Ambiguity and uncertainty in probalistic inference', Psychological Review, 92(4): 433-461.

Falk, A. \& Kosfeld, M. 2006. 'The hidden costs of control', The American Economic Review, 96(5): 1611-1630.

Farjoun, M. 2010. 'Beyond dualism: Stability and change as a duality', Academy of Management Review, 35(2): 202-225.

Fontin, M. 1997. 'Das Management von Dilemmata Erschließung neuer strategischer und organisationaler Potenziale'. Gabler \& doctoral dissertation. University of St. Gallen.

Gupta, A. K., Smith, K. G. \& Shalley, C. E. 2006. 'The interplay between exploration and exploitation', Academy of Management Journal, 49(4): 693-706.

Haas, M. R. 2010. 'The double-edged swords of autonomy and external knowledge: Analysing team effectiveness in a multinational organisation', Academy of Management Journal, 53(5): 989-1008.

Hamel, G. 2007. The future of management. Boston: Harvard Business Press.

Harris, C. J. \& White, I. 1987. Advances in command, control and communication systems. London: Peregrinus.

Hexmoor, H. 2002. 'A model of absolute autonomy and power: Towards group effects', Connection Science. 14(4):323-333.

Jacques, E. 1985. 'A look at the future of human resources via stratified systems theory', The Human Resources Planning, 8(4): 233-237.

Johnson, B. 1996. Polarity management. Amherst: HRD Press. 
Kaplan, R. S. \& Norton, D. P. 1996. 'Using the balanced score card as a strategic management system,' Harvard Business Review, 74(1):75-85.

Klein, H. 1989. 'An integrated control theory model of work motivation', Academy of Management Review, 14(2): 150172 .

Lambe, C. J., Webb, K. L. \& Ishida, C. 2009. 'Selfmanaging selling teams and team performance: The complementary roles of empowerment and control', Industrial Marketing Management, 38(1): 5-16.

Langfred, C. W. 2000. 'The paradox of self management: Individual and group autonomy in work groups', Journal of Organisational Behaviour, 21: 563-585.

Langfred, C. W. 2004. 'Too much of a good thing? The negative effects of high trust and autonomy in selfmanaging teams', Academy of Management Journal, 21: $563-585$.

Langfred, C. W. 2007. 'The downside of self management: A longitudinal study of the effects of conflict on trust, autonomy, and task interdependence in self-managing teams', Academy of Management Journal, 50(4): 885-900.

Larsson, J., Vinberg, S. \& Wiklund, H. 2007. 'Leadership, quality and health: Using McGregor's X and Y theory for analyzing values in relation to methodologies and outcomes', Total Quality Management, 18(10): 1147-1167.

Lee, J. Q., McInerney, D. M., Liem, G. A. \& Ortiga, Y. P. 2010. 'The relationship between future goals and achievement goal orientations: An intrinsic-extrinsic motivation perspective', Contemporary Educational Psychology, 35(4): 264-279.

Lee, W. 1999. Using qualitative methods in organizational research. California: Sage Publications Inc.

Lewis, M. 2000. 'Exploring paradox: Toward a more comprehensive guide', Academy of Management Review, 25(4): 760-776.

Luo, Z.-Q. \& Zhang, S. 2008. 'Dynamic spectrum management: Complexity and duality', IEEE Journal of Selected Topics in Signal Processing, 2(1): 57-73.

Lusher, L. S. \& Lewis, M. W. 2008. 'Organizational change and managerial sensemaking: Working through paradox', Academy of Management Journal, 51(2):21-240.

Marshall, C. \& Rossman, G. B. 2006. Designing qualitative research ( $4^{\text {th }}$ Edition). London: Sage Publications Ltd.

McGregor, D. 1960. The human side of enterprise. New York: Mcgraw-Hill.

Millikin, J. P., Hom, P.W. \& Manz, C. C. 2010. 'Selfmanagement competencies in self-managing teams: Their impact on multi-team system productivity', The Leadership Quarterly, 21(5): 687-702.

Nayar, V. 2010. 'A maverick CEO explains how he persuaded his team to leap into the future', Harvard Business Review, 88(6):110-113.

O'Reilly, C. \& Tushman, M. 2007. Ambidexterity as a dynamic capability: Resolving the innovator's dilemma. Stanford Graduate School of Business Research Paper Series, pp.1-61.

Pink, D. 2009. Drive. New York: Penguin Books.

Rhinesmith, S. H. 2001. 'How can you manage global paradox?' The Journal of Corporate Accounting \& Finance, 12(6): 3-9.

Rijamampianina, R. \& Carmichael, T. 2005. 'A framework for effective cross-cultural co-option between organisations', Problems and Perspectives in Management, 3(4): 92-103.

Ritzer, G. 1993. McDonaldization of society. London: Pine Forge Press.

Ryan, R. M. \& Deci, E. L. 2000. 'Intrinsic and extrinsic motivatons: Classic definitions and new directions', Contempory Educational Psychology, 25(1): 54-67.

Saunders, M., Phillip, L. \& Thornhill, A. 2009. Research methods for business students ( $5^{\text {th }}$ Edition.). Essex, England: Pearson Education Limited.

Serretta, H., Bendixen, M. \& Sutherland, M. 2009. 'Core corporate governance dilemmas facing boards: A South African perspective', South African Journal of Economic and Management Science, 12(2):194-210.

Sieber, L. 2008. 'The employability paradox'. Unpublished MBA research report, Gordon Institute of Business Science, University of Pretoria.

Simons, R. 1995. Levels of control. Boston: Harvard Business School Press.

Smith, K. \& Berg, D. 1987. Paradoxes of group life. San Fransisco: Jossey-Bass.

Smith, M. 2000. 'Exploring paradox: Toward a more comprehensive guide', Academy of Management Review, 25(4): 760-776.

Smith, W. K. \& Lewis, M. W. 2011. 'Toward a theory of paradox: A dynamic equilibrium model of organizing', Academy of Management Review, 36(2): 381-403.

Taylor, M. 2010. 'Does locus of control predict young adult conflict strategies with superiors? An examination of control orientation and the organisational communication conflict instrument', North American Journal of Psychology, 12(3): 445-458. 
Tharenou, P., Donohue, R. \& Cooper, B. 2007. Management research methods. Melbourne: Cambridge University Press.

Tyler, E. R., \& Blader, S. L. 2005. 'Can business effectively regulate employee conduct? The ancedents of rule following in work settings', Academy of Management Journal, 48(6):1143-1158.

Van den Steen, E. 2010. 'On the origins of shared beliefs (and corporate culture)', RAND Journal of Economics, 41(4): 617-648.

Verhoest, K., Peters, G., Boukart, G. \& Vershuere, B. 2004. 'The study of organisational autonomy: A conceptual review', Public Administration and Development, 24(2): 101-118.

Wageman, R. 1995. 'Interdependence and group effectiveness', Administrative Science Quarterly 40:145180 .

Welman, C., Kruger, F. \& Mitchell, B. 2005. Research methodology ( $3^{\text {rd }}$ Edition). Cape Town: Oxford University Press.

Zikmund, W. 2003. Business research methods. $\left(7^{\text {th }}\right.$ Edition). Mason: Thomson South-Western. 